\title{
The Peer Feedback Strategy in Teaching Writing
}

\author{
Mohammad Febryanto, Danny G. Nugraha \\ Jurusan Bahasa Inggris, Politeknik Negeri Bandung, Indonesia \\ Email: m.febryanto@polban.ac.id, danny.nugraha@polban.ac.id
}

\begin{abstract}
Peer feedback is a strategy that enables the students to trigger the writing learning process, and this study was conducted to figure out the aspects involved in the peer feedback. The research design is a case study through a qualitative and descriptive method based on questionnaire and observations involving 58 students of the 3-year Diploma of Business Administration Study Program. The result shows that the focus they took was the grammatical aspect which implies their own barrier.
\end{abstract}

Keywords: writing, peer feedback.

\section{BACKGROUND}

Based on one of the objectives included in the English subject given to the students of Business Administration, at the end of the program the graduates should have the ability in different forms of business writing. As asserted by Alwisalah (2005), writing requires the most effort as it involves a number of skills such as language use which inludes grammar, vocabulary use, acceptable phrases, coherence, cohesion and organizations. Furthermore, Shih cited in Brown (2001), states that a good writing work primarily depends on the process. Similarly, Hayland (2003) also states that the process of writing involves prepareation stage to express an idea through writing a draft which should go through editing and revision to produce a final draft. Essentially, the bigger the effort put on the process, the better the end result of writing should be. The editing may as well include the whole lot such as the content, organization, coherence and cohesion, grammar and the mechanic. Thus, proofreading involving feedback will always go with editing, revising.

As stated by MacArthur (2007) in the process of writing as such can result in the quality of writing and one way of revising involves an interaction either it be between team editors or editors. Similarly the peer feedback technique can serve as a learning 
strategy to teach writing by involving the students both as the writers and the editor. This enables them to interact within small groups or pairs in which they will naturally give comment on whatever they come up in related to the writing work. In the end they will use their own acquired knowledge of the language and how they perceive in understanding it. There will also be empowerment taking place without any psycholigal burden.

In addition through this classroom activity, the awareness of making mistakes will take place as Pennstate (2007) asserts that feedback is a strategy that helps improve not only the writing work but also the learning process in using the language. Thus, this study is an attempt to improve their awareness in the language use in learning writing.

\section{PROBLEM IDENTIFICATION}

The main concept of peer feedback is concerned with a collaborative work group that can promote independent learning involving their responsibility in trying to help their classmates' work. The study then attempts to investigate thorugh the following questions:

(1) What area of language do they focus in the process of giving feedback?

(2) What are the constraints encountered during giving feedback?

\section{THEORETICAL BACKGROUND}

Two previous relevant studies, Alasdair Blair and Samantha McGinty (2010), "Peer feedback: An effective approach to feedback delivery?" and Jos J.M. Baeten (2016), "The Power of Peer Feedback: Research on the Learning Process", basically have proven to enhance the process of learning based on internal motivation and making better awareness.

The next previous studies, "The Effects of Integrating Peer Feedback into University-Level ESL Writing Curriculum: A Comparative Study in a Saudi Context" by Grami Mohammad Ali Grami (2010) and "Effects of Teacher and Peer Feedback on Students' Writing at Secondary Level" by Tahira (2015) come up with common findings about the integrated learning strategy which show high effectiveness in 
different aspects of learning approaches such as the natural process in which interaction happens and the awareness and responsibility apart from the high possibility about the language learning itself. Therefore, the peer feedback strategy may bring about effective learning strategy with high motivation. This may be a significant approach in the curriculum to be embedded.

\section{Coherence and Cohesion}

Apart from the importance of the main idea, there are two aspects which have become the main concern for every writer and writing teachers, namely coherence and cohesion. In delivering ideas in writing, these two aspects become one of the parameters to see whether the writing has been able to express the unity of ideas in harmony. As expressed by Taylor and Francis (1996), cohesion can consist of local and global levels. This means that from the vocational discourse presented in several paragraphs and ideas that have a logical relationship, it is called a global coherent. Whereas in one paragraph, ideas presented in sentences that are logically related, then this is categorized as local coherence.

Texts can be coherent at what is called the 'local level' and the 'global level.' Local-level coherence is that which occurs within small portions of texts, usually within texts no longer than a paragraph. A text is said to have global coherence, on the other hand, if the text hangs together as a whole. (Duane H. Roen, "Coherence." Encyclopedia of Rhetoric and Composition: Communication from Ancient Times to the Information Age, ed. by Theresa Enos. Taylor \& Francis, 1996)

The cohesion is a device in the form of pronouns, conjunctions and structures that function to make the sentences flow coherently as stated in the quotation below:

Flow, those visible links which bind the sentences of a paragraph, can be established in two basic ways...The first is to establish a master plan at the beginning of the paragraph and to introduce each new idea by a word or phrase that marks its place in the plan. The second concentrates on linking sentences successively as the paragraph develops, making sure that each statement connects with the one or 
ones preceding it. (Thomas S. Kane, The New Oxford Guide to Writing. Oxford Univ. Press, 1988)

Chalmers (2017) also emphasized that coherence and cohesion are very important to help readability in conveying ideas. Coherence is a unity of ideas while cohesion is a unity of structural elements. One way to use these two aspects is through the use of cohesive tools, namely: logical bridges (repetitions), verbal bridges (synonyms), connecting words, and clear back referencing. (Chalmers, accessedon 4.32, 19 September 2017 dari http://writing.chalmers.se/en/75-coherence-cohesion)

If this tool is not found in the text, then it not only becomes more difficult to read the text, but also to understand its contents because the reader has to guess how the paragraphs or text are connected, and the reader has to read over and over again.

With logical bridges, the same idea of a topic is carried over (repeated) from sentence to sentence, and successive sentences can be built in parallel form. With verbal bridges, keywords or synonym words can be repeated, pronouns can replace nouns and transition words can be used. In the paragraphs below, words and expressions that work to increase the coherence of paragraphs are highlighted and underlined. As an example of this paragraph, coherence and cohesion in a paragraph are made by combining more than one device as presented in the following example:

There are three components to a typical modern catalytic converter: one to effect the reduction of nitrogen oxides, another to facilitate the oxidation of carbon monoxide and hydrocarbons, and the third to maintain the correct abundance of oxygen. In the first stage the nitrogen oxides are reduced using a platinum catalyst, which facilitates their decomposition into nitrogen and oxygen. In the next stage the carbon fragments are oxidized over a platinum/rhodium catalyst. Finally, the correct amount of oxygen is ensured by monitoring the amount of oxygen passing into the engine, and by incorporating into the catalyst a metal oxide that absorbs oxygen (by reacting with it to form a higher oxide) when the fuel mixture has too much oxygen and reverts to the lower oxide, releasing oxygen, when the mixture has too little (Atkins. P.W, 1991) 


\section{Grammar}

The next aspect covered in writing is of course how the writer applies the rules of language that apply in the language he uses. The rules of language are very broad in scope ranging from mechanical (spelling, use of punctuation and word capitalization), use of forms and types of words to the structure and types of sentences.

All manuals, lessons and curriculum for writing always start with the correct use of the rules. Saaristo also stressed that the ability to use grammar is a very basic "literacy". And this is also confirmed by a guidebook released by the Department of Education in the UK Department for Education and Employment that this ability is a very basic literacy strategy before they can read and write.

It can be concluded that grammar is an inseparable element in writing because every understanding of words, phrases and sentences is raised through correct grammar.

\section{Vocabulary}

The next essential aspect is the use vocabulary. Mofarehalqahtani in his article entitled "The importance of vocabulary in language Learning and how to be taught" concluded that

... that vocabulary mastery is an individual's great skill in using words of a language, which is acquired based on their own interests needs and motivation. Vocabulary mastery plays an important role in the four language skills and it has to be considered that vocabulary mastery is one of the needed components of language.

Similarly, Seyed Amir Solati-Dehkordi\&HadiSalehi (2016) in a journal article entitled "Impact of Explicit Vocabulary Instruction on Writing Achievement of UpperIntermediate EFL Learners" in his analysis confirmed that "A key factor in every day oral and written communication and academic success is Learners' vocabulary size which also has serious implications." In other words, the ability to master vocabulary including writing has an inseparable role.

In other words, vocabulary mastery is an individual's skill that is usually related to the fields and interests that give rise to the need to master it; so this component is needed. 


\section{Writing process}

There are several stages or processes in writing. According to Tynjala, Mason and Lonka (2001) within the process-centered paradigm for teaching L2 writing, student writing is evaluated on the quality of prewriting, writing, and revision. Hyland (2003) says that the writing process consists of Selection of topics, Prewriting, Composing, Response to draft, Revising, Response to revisions, Proofreading and editing, Evaluation, Publishing, Follow-up tasks. As for the other stages conveyed by Richards and Renandya (2002: 316) that the writing process consists of four basic stages namely planning, designing, revising, and editing. Although the stages may not be as comprehensively applied as in the real writing activity, the teachers may extract the process in accordance to the time setting.

\section{Feedback}

Feedback has become one essential part in the learning. As stated by Bloxham and Boyd (2007) that Feedback is often described as the most important aspect in the assessment process in improving achievement. In addition, feedback can be used as a component in signifying and improving the writing experience, and most importantly, as Saddler (2009) stated, it is to reflect student's recognition on the work and to show what they actually learn.

\section{Peer Feedback in the Strategy of Teaching Writing}

Much has been said about the benefit of collaborative learning, and peer feedback is one way to enhance awareness of learning motivated from withing the students. Here are some advantages of using peer feedback in the writing process. Tynjala, Mason and Lonka (2001) argue that the feedback process gives students the opportunity to practice their new strategy and have the opportunity to receive feedback so they can polish their expertise. Medonca and Johnson (1994) assume with feedback students can actively participate in learning while getting responses from real readers in non-threatening situations. In addition, students not only benefit from seeing how readers understand their ideas and what they need to improve their writing, but also gain the skills needed to critically analyze and revise their writing (Leki, 1990; Zhang, 1995).

Hyland (2003) also argues that there are several advantages to using peer feedback in writing. First, it makes students active in participating. Second, the discussion occurs in the real contexts. Third, there is no assessment. Fourth, readers are 
other and real choices. Fifth, the writer gets an understanding of the reader's needs. Sixth, reduce fear of writing. Seventh, develop critical reading skills, and finally, reducing the workload of teachers.

According to Ferris, there are practical benefits from using peer feedback as follows:

a. Reading other writings makes it possible to be more critical in thinking, more confident, and have a good perspective.

b. Students get more feedback about their writing than they get from the teacher.

c. Students can get more feedback from diverse perspectives.

d. Students get feedback from non-professional readers when their writing is unclear because of ideas and language.

e. Peer feedback activities can make students have better social interactions.

\section{METHODOLOGY}

This research used a qualitative approach. According to Ivankova and Creswell (2009) qualitative research is a study that does not take measurements and qualitative research aims to understand the experience of the object as the focus of research. Deeptee and Roshan (2008) design that allows for a researcher to explore beliefs, behavior, interactions, perceptions, attitudes, feelings and motivations as well as to understand how they are formed.

\section{Setting and Respondents}

This research took place in PoliteknikNegeri Bandung, especially the Department of Commerce. The respondents were students of D3- Business Administration of 5 semester consisting A class and B class. A Class had 28 students and B Class had 30 students, so there were 58 students in total. Selection of research respondents is based on the purposive sampling. Arikunto (2010) said that purposive sampling is a technique for taking research samples that are not based on strata, random or area but based on specific objectives. Likewise, according to Sugiyono (2010) states that purposive sampling is a technique for determining respondents by considering certain things. Therefore, purposive sampling is used as a technique to determine respondents because it considers certain aspects as follows: 
1) D3 study program students in Bandung State Polytechnic Business Administration,

2) Contracting Business Reading and Writing courses,

3) Having knowledge and experience in writing.

\section{Data Collecting}

To get adequate data, this research used three instruments, namely observation, student written documents and questionnaires. The three instruments are used as data triangulation so that the data obtained can mutually reinforce and answer research questions comprehensively. Creswell (2012) states that triangulation combines the strengths of different types of methods to enrich investigation and to minimize the weaknesses of other methods.

\section{Students Writing Works}

The documents analyzed in this study are the results of student writing. There are also student writing is paragraph-shaped writing. There are four results of student writing with a number of words around 100-200 words. The first article is writing about company profile. The second article is about work in business. Third, writing about factors that influence behavior or habits in work/ study. Finally, the fourth article about why they are loyal to certain brands.

The results of the writing before and after being given feedback will be analyzed to see what the focus is in providing feedback and the constraints experienced in providing feedback. The aspect seen from the writing is the changes that occur such as spelling of words, vocabulary, punctuation, grammar, paragraph structure and context.

\section{Observation}

The type of observation used in this study is participant observer. A participant observer is an observer who is involved in the activity when they observe the activity (Creswell, 2012). Researchers played an active role during the teaching process of writing and see feedback activities as the revision process takes place. This is done to guide students in the process review the posts to match what they should. Every important event regarding the focus and obstacles in the feedback made by students is 
recorded on the observation sheet Observation will be done 4 times and observations will be made on all students.

\section{Questionnairre}

Questionnaires given to respondents aimed to obtain their focus in providing feedback, the quality of their writing after being given feedback, obstacles in providing feedback and the impact on motivation in writing. The types of questionsused in this study were closed questions. The questionnaire was given at the last meeting in the field and was given to all respondents.

\section{Data Analysis}

Systematically analyzing the data in this study was conducted as suggested by Miles and Huberman (1984 in Silverman, 2005) with systematic as follows. The first is data reduction or data reduction. According to Miles and Huberman (1994) this analysis phase refers to the process of selecting, focusing, simplifying, and transforming the data that emerges. In this study, the data reduction process goes hand in hand with data collection. At the time of data collection there was certainly a lot of data obtained from the field - data from observations, written documents and questionnaires. Therefore, data reduction is needed to simplify the data collected.

\section{RESULT AND ANALYSIS}

The observation was conducted four times, i.e. on 6, 13 October 2017 and 3,10 November 2017 involving 50 students, or, in this study, they are identified as s1, s2, through to s 50 (first student, second student through fiftieth student). The observation was conducted from day one through day four as elaborated below:

\#Day One

The first observation was on Friday 6 October 2017. First the respondents were told to exchange the writing they had made in the previous meeting with the friend next to them. Respondents were given a guide to evaluate or revise the results of the writing in order to facilitate them in providing feedback. The topic of the writing is about a company profile. The first step was to read the writings of their friends to understand the contents of the message of the writing. 
In the process of understanding the contents of their friend's work, there were several respondents who used dictionaries to look for the meaning of certain words, as did the 50 students. The students always used a dictionary to look for words that were not understood. It has been noted that one respondent, s34, translated first into Indonesian to understand the contents of the writing; whereas 4 other respondents tried to figure out the verb agreement in their friends' writing.

\section{\#Day Two}

The second observation was made on Friday 13 October 2017. The process and steps were carried out the same as in the first observation. The respondents exchanged their writings for their friends to read so that they could be given input to their writings. First, they read the writings of their friends to understand the contents of the writing then comment on it.

The observation also showed that the respondents gave feedback starting from the easiest such as spelling of words. They can easily identify word writing errors. But there are also some students who open the dictionary on their smartphone to see how to spell or write the correct word as done by s1, s34 and s50.

In addition to spelling words, respondents also noticed grammatical errors such as auxiliary and plural verbs (is, are, has, have), transition words such as first, second, therefore. The feedback they provide in grammatical aspects is very limited because if they are paid attention to, they only correct mistakes that are easy to identify such as simple sentences, for complex sentences they have not been able to correct them.

This can be seen when the writer went around seeing how their process provides feedback, most of the respondents asked questions in grammar that they did not understand. Students 10, 14, 18, 22, 40, 48, 50 and 54 face difficulties in $\mathrm{s}+\mathrm{v}$ agreement. They are confused in deciding which subject and verb to use. Besides students 45 and 47 do not realize that in the writing they read there are two sentences that are combined in one sentence (run-on sentences). When finished they return the results of the feedback to their friends to be corrected. 
\#Day Three

On Friday the 3rd November 2017 the third observation was held. The process and steps were the same as in the first observation. The respondents exchanged their writings for their friends to read so that they could be given input to their writings. First they read the writings of their friends to understand the contents of the writing then comment on it.

The feedback process in the third observation, it is still seen that the respondents are still starting to provide feedback from starting as simple as punctuation for the use of commas. After that they focus on spelling each word. In the process of feedback the confusion still occurs as students are still confused in the sentence structure, This can be seen when he analyzes the sentence to find errors can not identify the correct sentence structure. Based on observations on the third day, the respondents still found obstacles in providing feedback from their friend's writing.

\section{\#Day Four}

The fourth most recent observation was carried out on November 10, 2017. The process and steps taken were the same as in the first observation. The respondents exchanged their writings for their friends to read so that they could be given input to their writings. First they read the writings of their friends to understand the contents of the writing and then commented on it.

In the fourth observation the respondents continued to do so by giving feedback starting from the easiest such as spelling of words. They can easily identify word spelling mistakes. But students 50 use the smart phone to translate sentences to understand the contents of the text. Vocabulary or choice of words did not escape the attention of respondents as did by students 1, 10, 20, 29, 52 .

Then the respondents paid attention to grammatical errors such as subject and verb agreement. Students 23, 25, 28 began giving feedback related to subject and verb agreement. But there are still many who are confused in paying attention to the subject and verb agreement. They look still confused in determining which subjects and verbs to use. When finished they return the results of the feedback to their friends to be corrected. 


\section{Result from their Feedback}

The writings of the respondents consisted of four pieces of writing. The topics written are first about the company profile (Writing 1), second about the work that makes it possible for graduates of the Business Administration study program (Writing 2), third about what factors affect the nature and habits of work / study (Writing 3), and which Finally, what is the reason for being loyal to a product (Article 4). The table below is the recapitulation result that was the focus of the respondents' writing in providing feedback.

Table1 Result of Feedback

\begin{tabular}{|l|l|c|c|c|c|c|}
\hline & \multicolumn{1}{|c|}{ Aspect } & Writing1 & Writing 2 & Writing3 & Writing4 & Total \\
\hline 1 & Topicsentence & 1 & 0 & 0 & 0 & 1 \\
\hline 2 & Supportingsentences & 2 & 1 & 1 & 1 & 5 \\
\hline 3 & Supportingdetails & 6 & 5 & 5 & 5 & 21 \\
\hline 4 & Conclusion & 20 & 17 & 15 & 12 & 64 \\
\hline 5 & Grammar & 80 & 71 & 68 & 70 & 289 \\
\hline 6 & Punctuation & 36 & 38 & 35 & 37 & 146 \\
\hline 7 & Transition & 12 & 11 & 10 & 8 & 41 \\
\hline 8 & Vocabulary & 14 & 21 & 17 & 15 & 57 \\
\hline 9 & Spelling & 15 & 22 & 20 & 18 & 75 \\
\hline
\end{tabular}

Based on the above table, it can be seen that there is only 1 feedback on the topic sentence aspect that is in the first writing. The second aspect of supporting sentences is found in 5 cases. Supporting details which is the 3rd aspect are available in 21 casess. Meanwhile, the conclusion is in 64 cases. There are 289 cases on grammar and 146 on punctuation. For the Transition aspect there are 41 cases. Then the vocabulary aspect is in 57 cases. The last spelling aspect is found 75 cases.

\section{Result of Questionnaires}

The questionnaire was given to respondents on November 17, 2017. The use of the questionnaire aimed to find out what was the focus of the respondents in providing feedback and the obstacles they faced when giving feedback. Here are the results of the questionnaire regarding the focus being feedback.

Table2 Focus of the Feedback

\begin{tabular}{|l|l|r|}
\hline & \multicolumn{1}{|c|}{ Aspect } & Total \\
\hline 1 & Paragraph structure & 5 \\
\hline 2 & Grammar & 20 \\
\hline
\end{tabular}




\begin{tabular}{|r|l|r|}
\hline 3 & Punctuation & 30 \\
\hline 4 & Vocabulary & 35 \\
\hline 5 & spelling & 25 \\
\hline 6 & Content & 3 \\
\hline
\end{tabular}

Based on the results of the questionnaire, there are six aspects that are the focus in providing feedback. Highest is vocabulary. There were 35 respondents who answered that their focus was vocabulary. Then the punctuation aspect is around 30 respondents followed by the spelling of the words of about 25 respondents. Another aspect that is the focus is grammar with a total of 20 respondents. Then the paragraph structure became the focus of 5 respondents. Last is the content aspect with about 3 statements.

Table3 Feedback Constrains

\begin{tabular}{|c|l|c|}
\hline & \multicolumn{1}{|c|}{ Aspect } & Total \\
\hline 1 & Grammar & 35 \\
\hline 2 & Vocabulary & 20 \\
\hline 3 & Content & 1 \\
\hline
\end{tabular}

Based on the results of the questionnaire, there are also three aspects that become obstacles in providing feedback. The highest is grammar. There were 35 respondents who answered that their obstacle was grammar. Then in the vocabulary aspect there are about 30 respondents who stated this. Last is the aspect of content with about 1 respondent who included in the feedback.

\section{Analysis}

Looking at the percentage and proportion of the amount of feedback they make, the most is the feedback related to grammar that is $40.76 \%$ almost half. This shows that not only the highest focus was concentrated on grammar correction but also the awareness of English grammar was also high, even though the results of the questionnaire showed that the perception of focus that they had on grammar was not the highest. However, the obstacle to giving feedback lies in the grammar. Thus, they may already have an awareness of the accuracy of examining the grammar. This is like what 
Saaristo did, he stressed that the ability to use grammar is a very basic "literacy". This shows that the respondents have the capital to write well.

The second largest proportion is the use of punctuation, which is $20.59 \%$, which actually can be categorized as basic (mechanical) grammar. Examination to the stage of punctuation also indicates their perception of accuracy and awareness of the importance of punctuation. Their perception even appears the highest from the results of the questionnaire.

A balanced proportion appears in conclusions, vocabulary and spelling (approximately 9-10\%). If the conclusion is categorized into content-related feedback, then vocabulary and spelling may be another indicator of their ability in language use, which is to select and spell (mechanical) words.

The content related to feedback on content is very small except the conclusion. Topic sentence and supporting sentence are less than $1 \%$. In fact, in writing, it is this aspect that plays an important role in the content. When we look at the perceptual aspects of the questionnaire and their perceptions about barriers, the content aspect is also very small and does not show its significance However, when the results of the writing are examined through a process of reviewing each other, most of their writings have not yet come up with a good paragraph formation. In fact, almost all writings are not clear paragraph divisions such as 2 pages consisting of only one paragraph. This actually makes it difficult to see where it starts (intro) and its contents. This means that the writer only spills and streams his ideas without considering his organization. This also means the topic sentence and supporting sentence appear vaguely and jump.

The above clearly shows that they still do not understand the writing organization, so it is not surprising that the feedback for the content and especially the organization is very small in concentration. While the aspect of conclusions can still be seen because they think that this aspect is at the end of the paper.

The transition aspect becomes a slightly larger part than the aspects of topic sentences and supporting sentences, 5,78\%. The role of the transition that should function as a bridge between one idea in one paragraph and another paragraph is not detected, but rather the sign-post markers, such as the word "example". Whereas McCutchen (1989) said that a good writer is someone who has the ability to deliver 
sufficient exposure, can use a connecting device between ideas, and who can regulate the language construction that expresses ideas in a unified discourse.

Tabel4Precentage of Feedback Focuses

\begin{tabular}{|c|l|c|c|c|c|c|c|}
\hline & \multicolumn{1}{|c|}{ Aspects } & Writing1 & Writing2 & Writing3 & Writing4 & Total & $(\%)$ \\
\hline 1 & Topicsentence & 1 & 0 & 0 & 0 & 1 & 0.14 \\
\hline 2 & Supportingsentences & 2 & 1 & 1 & 1 & 5 & 0.71 \\
\hline 3 & Supportingdetails & 6 & 5 & 5 & 5 & 21 & 2.96 \\
\hline 4 & Conclusion & 20 & 17 & 15 & 12 & 64 & 9.03 \\
\hline 5 & Grammar & 80 & 71 & 68 & 70 & 289 & 40.76 \\
\hline 6 & Punctuation & 36 & 38 & 35 & 37 & 146 & 20.59 \\
\hline 7 & Transition & 12 & 11 & 10 & 8 & 41 & 5.78 \\
\hline 8 & Vocabulary & 14 & 21 & 17 & 15 & 67 & 9.45 \\
\hline 9 & Spelling & 15 & 22 & 20 & 18 & 75 & 10.58 \\
\hline \multicolumn{7}{|l|}{ Total of items found in feedback }
\end{tabular}

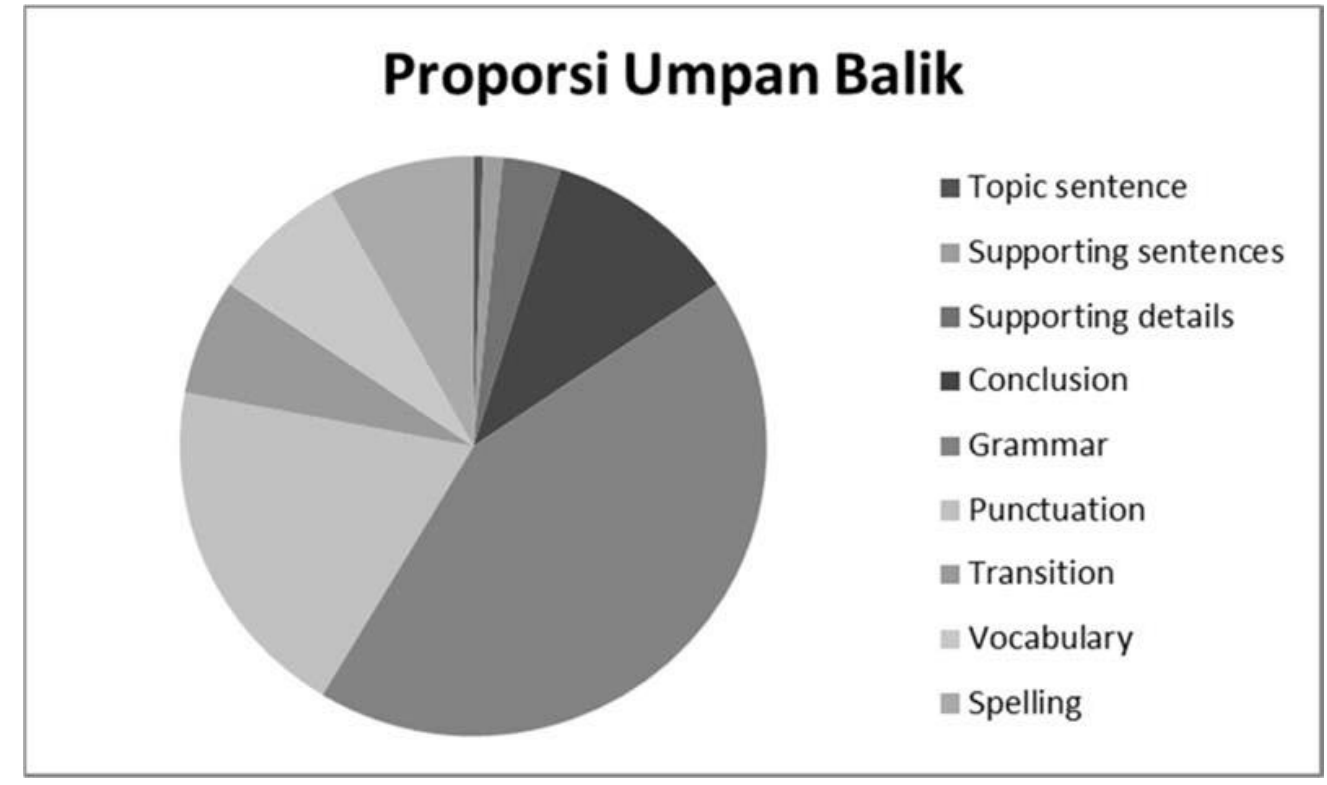

Diagram 1 Proportion Feedback Concentration

\section{Feedback Constrains}

The results of the questionnaire related to their perception of the obstacles in providing feedback gave rise to 3 aspects namely grammar, vocabulary and content. The following table below shows that out of 56 respondents, 35 had the perception that there were obstacles in the grammatical aspects $(62.5 \%)$. As explained in the previous section that constraints can be interpreted as their low competence, but it can also mean that awareness in checking takes precedence over grammar and vocabulary usage which takes precedence over the contents and organization. 
Table5 Feedback Constrains

\begin{tabular}{|l|l|l|}
\hline & Aspect & Total \\
\hline 1 & Grammar & $35(62.5 \%)$ \\
\hline 2 & Vocabulary & $20(35.71 \%)$ \\
\hline 3 & Content & $1(1.79 \%)$ \\
\hline
\end{tabular}

From the percentage figures above, it can be indicated that their perceptions in learning other languages are on differences in grammar, and in fact when they learn, the emphasis is on grammar. Their awareness of differences in grammar has become a big issue for EFL learners so far. The context aspect even though the percentage is small does not mean that aspect is not an obstacle. It is possible that these aspects are not the focus of feedback or maybe those who provide feedback do not understand the content. In terms of the clarity aspects of the organization and content become aspects that are actually more important.

The above facts can have implications for the causal relationship between the focus of feedback with the perception of the obstacles they face. The constraints can be positioned on the cause and the focus of the feedback becomes the effect. In other words it can be concluded that they are more focused on the awareness of the importance of grammar that is reflected in their feedback because they feel that aspects of grammar are a point of difficulty in learning other languages (English).

Another implication is that their awareness of good writing has not yet appeared to be important content. This is shown by the process of checking each other by the researchers that this aspect has not yet received attention both in the constraints and the feedback they made.

\section{CONCLUSION}

Based on the findings and discussion in chapter four, it can be seen that the first focus of the respondents when giving feedback on their friends' writing was on the grammatical aspects of around 50\%. This shows that the respondents already have an 
awareness of one aspect of language that is grammar. This also shows that grammar will not go unnoticed if they provide feedback in the future.

The second conclusion that can be drawn is the obstacle faced by respondents, namely grammar. Even though grammar was their focus in providing feedback, respondents still experienced obstacles in understanding grammar. They actually feel worried if the feedback they give is not as it should be.

The above can also be related to their awareness and concern for the importance of grammar in learning foreign languages (EFL), so that both their perceptions of constraints, focus, and the results of the percentage of feedback are in the grammatical aspects.

Therefore, it is very important in equipping students with knowledge of aspects in writing. Because grammar is the focus of the review aspect it is necessary to strengthen their understanding of grammar. In addition, in teaching writing it is also necessary to emphasize aspects of the content of writing because these aspects are very important.

\section{Acknowledgements}

This research has been funded by Politeknik Negeri Bandung in 2017 with contract number: Nomor: 381.14/PL1.R7/LT/2017

\section{REFERENCES}

Alwasilah, A. Chaedar. 2003. Pokoknya Kualitatif: Dasar-Dasar Merancang dan Melakukan Penelitian Kalitatif. Bandung: Pustaka Jaya

Arikunto, Suharsimi. 2013. Prosedur Penelitian: Suatu Pendekatan Praktik. Jakarta: RinekaCipta

Blair, Alasdair dan McGinty, Samantha. 2010. Peer feedback: An effective approach to feedback delivery. De Montfort University

Bloxham, S. dan Boyd, P. 2007. Developing Effective Assessment in Higher Education. New York: Open University Press.

Brown, H Douglas. 2001. Teaching by Principles: An Interactive Approach to Language Pedagogy. New York: Addison Wesley Longman, Inc. Chalmers, 
disitir jam 4.32, 19 September 2017 dari http://writing.chalmers.se/en/75coherence-cohesion

Creswell, J.C. 2012. Education Research, Planning, Conducting and Evaluating Quantitative and Qualitative Research. 4th edition. Boston: Pearson

Deeptee, Purmessur. R danRoshan, Boodhoo. 2009. Signalling Power of Divinden on Firms' Future Profit A Literature Review. International interdisciplinary Journal. New York: March 2009.

Duane H. Roen, 1996 "Coherence." Encyclopedia of Rhetoric and Composition: Communication from Ancient Times to the Information Age, ed. by Theresa Enos. Taylor \& Francis.

Falchikov, N. 2000. Learning Together: Peer Tutoring in Higher Education. New York: Taylor and Francis.

Ferris, Dana, R. 2003. Response to Student Writing Implications for Second Language Students. Mahwah, NJ: Lawrence Erlbaum Associates, Inc

Grami Mohammad Ali Grami. 2010. The Effects of Integrating Peer Feedback into University-Level ESL Writing Curriculum: A Comparative Study in a Saudi Context. Newcastle: Newcastle University School of Education, Communication and Language Sciences.

Harmer, Jeremy. 2001. The Practice of Teaching English. London: Pearson Longman

Harmer, Jeremy. 2007. The Practice of English Language Teaching 4th Edition. Essex: Pearson Education Limited.

Hyland, K and Hyland, F. 2006. Feedback in Second Language Writing Cambridge: Cambridge University Press.

Hyland, K. 2003. Second Language Writing. Cambridge: Cambridge University Press. Ivankova, N.V., and Creswell, J.W. 2009. Qualitative Research in Applied Linguistics A Practical Introduction. Great Britain: Mix Method. Palgrave Macmillan.

Langan, John. 2006. English Skill: Eight Edition, New York: McGraw Hill Higher Education. 
Jos J.M. Baeten. 2016. The Power of Peer Feedback: Research on the Learning Process within Virtual Action Learning. Nyenrode Business Universiteit: the Netherlands

Leki, I. (1990a). Potential Problems with Peer Responding in ESL Writing Classes. CATESOL Journal, 3, 5-19.

MacArthur, C. A. 2007. Best Practices in Teaching Evaluation and Revision. In S. Graham, C. A. MacArthur, \& J. Fitzgerald, Best Practices in Writing Instruction (pp. 141-162). New York: The Guilford Press. McCutchen, 1989. "Domain Knowledge and Linguistic Knowledge in the Development of Writing Ability"

MofarehAlqahtani "The importance of vocabulary in language Learning and how to be taught"

Ghani, MamunadanAsgher, Tahira. 2012. Effects of Teacher and Peer Feedback on Students' Writing at Secondary Level. The Journal of Educational Research. Vol. 15 , No.2

Maryam Bijami. 2015. Journal of Studies in Education, "Peer Feedback in Learning English Writing: Advantages and Disadvantages" School of Languages, Literacies, and Translation UniversitiSains Malaysia, 11800: Penang, Malaysia

Mendonça, C., \& Johnson, K. (1994). Peer review negotiations: Revision activities in ESL writing instruction. TESOL Quarterly, 28, 745-769.Meyers (2005)

Miles, M.B. and Huberman, A.M. 1994. Qualitative Data Analysis. California: Sage Publication Inc.

Murray dan Moore. (2006). Richards, J.C danRenandya, W. A. 2002. Methodology in Language Teaching: An Anthology of Current Practice. USA: Cambridge University Press. Sandelowski, Margarete. 2000. Focus on Research Methods: Whatever Happened to Qualitative Description? Research in Nursing and Health 23: $334-3340$.

Shih. 1986. Brown, H Douglas. 2001. Teaching by Principles: An Interactive Approach to Language Pedagogy. New York: Addison Wesley Longman, Inc. 
Saaristo, Pekka "Grammar is the heart of language: grammar and its role in language learning among Finnish University Students" https://jyx.jyu.fi/dspace/bitstream/handle/123456789/47198/296.pdf?seq uence $=1$,

Seyed Amir Solati-Dehkordi\&HadiSalehi, 2016, "Impact of Explicit Vocabulary Instruction on Writing Achievement of Upper-Intermediate EFL Learners"

Sokolik,M. 2003. Writing Skill. David Nunan (Ed.). Practical English Language Teaching. New York: McGraw Hill.

Straub. 2000. Hyland, K. 2003. Second Language Writing. Cambridge: Cambridge University Press

Sugiyono. 2013. MetodePenelitianKuantitatif, Kualitatif dan RD. Bandung: CV Alfabeta.

Thomas S. Kane. 1988. The New Oxford Guide to Writing. Oxford Univ. Press,

Tynjala, Paivi,Mason, Lucia, Lonka, K. 2001. Writing as a Learning Tool. Integrating Theory and Practice. Netherlands: Kluwer Academic Publisher.

Zhang, S. 1995. Re-examining the affective advantage of peer feedback in the ESL writing class. Journal of Second Language Writing, 4(3), 209-222. 